\title{
Towards an effective participatory process for a sustainable urban waterfront development
}

\author{
Yusri Syahrir* \\ Department of Environment, Health, and Safety, King Fahd University of Petroleum and Minerals, Dhahran 31261, Saudi Arabia
}

Article history:

Received: 18 March 2021 / Received in revised form: 9 June 2021 / Accepted: 13 June 2021

\begin{abstract}
During the early time of waterfront development, public only paid little attention to this area, but after a series of urban waterfront revitalization success story, people are starting to reclaim their waterfront. Two main values of economy and environment are always competing over waterfront's future land-use pattern. Citizen participation in an urban waterfront development is believed to hold a significant importance since the urban development is addressed for citizens' prosperity. However, strong public participation does not necessarily guarantee for a success waterfront development. This paper attempts to figure out what is the best scenario to make public involvement in the planning process to contribute to a successful and sustainable waterfront development. Four waterfront city development stories that represent different planning cultures were examined here to understand to what extent the participatory process contributed to the environment, economy, and social values. The findings from the case studies were reconstructed to develop a planning model aimed to best accommodate public interest without compromising other values. Citizens were invited for discussions at the initial phase. Next, an evaluation method was proposed to come up with a guideline that would guide the planning process at the latter phase.
\end{abstract}

Keywords: waterfront development; participatory process; urban revitalization; sustainable development: public involvement

\section{Introduction}

After years of revitalization efforts, many waterfront cities have successfully remade the image of their waterfront area, and continued to revive it after suffering from neglect for almost a century. The urban waterfront redevelopment phenomenon began in earnest in the 1960s pioneered by the well-known and highly publicized Baltimore waterfront redevelopment, and accelerated in the 1980s. Today, the competition of waterfront development is very obvious, and when the enormous potential of waterfront development projects for port cities becomes clear in economic, architectural, and (later) political terms, pressures on waterfront sites within cities start to build (Daamen \& Vries, 2013).

Participatory process in such urban waterfront redevelopment is also unique. In the beginning (during 1960s) public only paid little attention to this area, but after waterfronts revealed its enormous potentials, today people are starting to reclaim their waterfront.

Great achievements advertised by waterfront revitalization projects especially in Europe and North America have attracted many waterfront cities around the world to start rethinking about their shoreline territory. Waterfront development is very promising for promoting tourism, and some countries that typically have desert landscapes such as Saudi Arabia, Qatar,

* Corresponding author. Tel.: +966-536-171-501.

Email: yusri@kfupm.edu.sa

https://doi.org/10.21924/chss.1.1.2021.6 and United Arab Emirates are now joining the race to develop the largest and the most luxurious waterfront projects with strong financial support thanks to the massive oil and gas reserve they have.

Public participation in an urban waterfront revitalization project is very important since the project is intended to improve ecology and economy condition of the area without compromising the public interests and social equity among citizens. This paper studied what the best scenario of public involvement during the waterfront revitalization process is. Four waterfront development stories, one story from each of Spain and China, and two from the U.S. are presented here because we found these four waterfront development projects shared different approaches about how to involve their citizens in the planning process. The findings from the examination of these four different approaches of public participation were then reconstructed to develop an effective participatory process for a sustainable urban waterfront development.

Participatory process in urban waterfront revitalization seems different and unique since a democratic participation in reshaping policy on this territory did not always go along with its success story. A number of waterfront development stories revealed that full and strong public participation did not necessarily guarantee the success of the waterfront development. The complexity on the urban waterfront leads to different views in how to develop the area. Thus, increasing dialogue between those parties is very essential to define a sustainable waterfront area. 
A comparative study that puts together different waterfront development stories sharing a different planning culture as presented in this study is deemed essential to understand how public participation should be positioned in a waterfront project. Many literatures discuss the technical aspect about involving public participation such as using information and technology systems. This study attempted to draw a general framework about where and when to involve public participation in a waterfront development project to have an effective participatory process for a sustainable urban waterfront development.

\section{Methodology}

This paper drew upon a literature review of books available in the main library of King Fahd University of Petroleum and Minerals (KFUPM), Dhahran, Saudi Arabia and open access journals/ papers that are available online. The article selection was mainly focused on three subjects: waterfront development, public participation, and urban revitalization.

\section{Lesson learned from waterfront development projects around the world}

This section discusses about four urban waterfront developments from three different countries with different cultures in their planning process. From these case studies, we attempted to examine what factors are behind the failure and success stories of redeveloping their waterfronts and how the participatory process took place in the planning process.

\subsection{Bilbao, Spain}

The city of Bilbao, the capital of the Biscay province of the Basque County on the Atlantic coast of northern Spain is situated in the valley and estuary of the Nervion River. In the nineteenth century, Bilbao was developed into an industrial center. But in the beginning of the last quarter of the century the situation changed, the Spanish economy declined. The departure of industrial era leaved the city with environmental decay and urban stagnation.

Bilbao's story is a remarkable waterfront revitalization effort for how a city with industrial character can rework that image to be one of a major centers of culture in Europe. Starting in 1992, there has been an attempt to incorporate strategic planning as a major tool to drive the process of economic regeneration in Bilbao (Gomez, 1998). The plan promoted redevelopment for the environmentally degraded areas and revitalized the riverside to reinvent Bilbao as the banking capital of Spain.

The city fully realized that a key element in the success of revitalization project would be achieved through the understanding and the coordinated effort between the public administration and the private sector (Marshall, 2001). In field, the remaking of the image of the city is actually being propelled by a series of architectural projects. The architects were invited to participate in the international design competition that focused to reposition of the city as a world-class metropolis. A public-private initiative, called as Bilbao Ria 2000, the scheme includes the number of master pieces of contemporary architecture including the celebrated Guggenheim Museum designed by Frank O. Gehry. Despite the clarity of the vision and the commitment of communities to the revitalization efforts, a series of great architecture projects apparently acted as the backbone of the waterfront development over a period of some fifteen years.

\subsection{Shanghai, China}

The city of Shanghai, located along the Huangpu River, is considered as one of the largest cities in the world. In the middle of twentieth century, Shanghai became an industrial power house and the economic engine for all of China. During the period of open reform in the 1990s, this city suffered from financial crisis and left the city in desperate need of investment for updating it urban infrastructure.

In the middle of 1990 s, Shanghai started the waterfront renewal project. The project aimed to revitalize the riverbank including the environment quality improvement by reorganizing the urban development of the surrounding area, and establishment of new parks together with the preservation of the historical areas. The remarkable achievement of the renewal project was obvious. Given the speed and size of construction in the waterfront, environmental regeneration issues and urban water's edge redevelopment were so heavily concerned on the minds of decision-makers (Marshall, 2001). The government has initiated several measures to address air pollution, solid waste production, and the treatment of wastewater and the greening of urban areas including the waterfronts.

Planning in China is considered as a sole responsibility of government (Friedman, 2005). A politically civil society does not exist and citizen role in planning process is very limited. As a consequence, top-down decision and policymaking are a common sense in China. Critical to successful planning in remaking the image of the city is collaboration between the Shanghai Port Authority, the Shanghai Urban Planning and Urban Research Institute, and the private sectors that prepared the development framework for investment, marketing, and coordination of the waterfront.

\subsection{Baltimore, Maryland, U.S}

Baltimore is located along the Patapsco River; the city is recognized as one of the leaders of the waterfront redevelopment movement and hailed as one of the greatest urban waterfront success stories in the world. After the Second World War, the emergence of the container shipping industry had contributed to the abandonment of old port. This event had prompted a ten-year decline in downtown property values; therefore, it led to a comparable reduction in the city's tax revenues (Millspaugh, 2003).

In the mid-1950s, business leader took initiative step to rescue the declining waterfront and hired the Wallace planning firm to design the Charles Center mixed-up development on 33 acres. Although not a comprehensive plan, the result was eye opening and hailed as a catalyst for city renewal. A more comprehensive plan was introduced later in 1964, namely the Inner Harbor Master Plan, and the voters quickly approved a bond issue of \$2 million to kick-start the program (Millspaugh, 2003). Immediately after this project, a series of large and small 
development projects soon followed.

Citizen opposition took place in 1978 when the city planned the replacement of some parks along the Light Street to allow new development for shops and restaurants. Referendum was held later with $54 \%$ voters in favor for new development after a major campaign for it by city and business interests (Breen \& Rigby, 1994). The development underway on the right direction and considerably reduced such opposition.

\subsection{Portland, Oregon, U.S.}

Portland "the city of roses" located in the United State of Oregon is blessed by the existence of two great rivers, namely Willamette River and Columbia Rivers. The history of Portland's waterfront zoning has been a mix of city and community planning along with a healthy dose of citizen activism (Davis, 2001). After industrial era, Portland waterfront development could be elaborated into two phases of development; the first phase was dominated by citizen activism to preserve the working waterfront and the second one was when economic value started to influence the development process.

After the industrial era passed, Portland started to reexamine the dilapidated waterfront and its uses. During 1970s-1980s, a series of proposal to re-zone the waterfront area for industrial and commercial use were rejected. It was because the citizens wanted to preserve Portland riverbank as a working waterfront and rejected to turn it over to large developers and condominiums to retain the main characteristic of their waterfront.

After twenty years, the City of Portland realized that their current stance had made Portland's waterfront in a state to shrink, and the area suffered from neglect, empty space and lack of investment (Breen \& Rigby, 1994). With the assistance of the Waterfront Alliance that consisted of various groups concerning with the waterfront, the city once again reexamined the current waterfront zoning and prepared a report on the zoning and its consequences. The results of the study showed that the city allowed non-marine used "only on a temporary basis and only to the extent it will not impede any future water dependent development" (Davis, 2001). Although not explicitly mentioned, a new policy offered new opportunities for developers. Years after the passage of re-zoning regulation, the city and the region have pinned their hopes for the future on real estate development, biotech and the creative economy (Hagerman, 2007).

\subsection{The Key Actors}

From four case studies presented above: Bilbao, Shanghai, Portland, and Baltimore, it can be concluded that there are, at least, five key actors influencing the direction of an urban waterfront development. All these actors are not necessarily exist in the planning process, and each has a different contribution in determining the success of waterfront revitalization. Table 1 summarizes the weight of contribution of each key actors in the urban waterfront development in each city.

Political Leader. In the case studies of Bilbao, Shanghai, and Portland ( $2^{\text {nd }}$ phase), the local government played an important role in initiating the revitalization projects. The visionary thinking of the leaders was essential in rescuing the declining parts of the city. A visionary leader always tries to figure out the city's future; so that necessary plans were introduced to transform the city image.

Private Business. From all case studies, the business community's role was critical to revive the dilapidated and neglected waterfront area to be a livable urban waterfront. This specific area needed a huge investment since the construction cost to redevelop this area was typically high because it dealt with the environmentally sensitive area and called for special technology.

Independent Organization - Non-Governmental Organizations (NGOs). A strong and healthy independent citizen organization was obvious in Portland case study, especially in the first development phase. Citizen activism built a close relationship with the local government, as well as educated citizens to preserve environment and cultural values along the waterfront. Aside from the economy stagnant, the existence of citizen activist was very crucial to counter any excessive economic forces.

Urban Designer. The Bilbao case has given a picture of how urban designers along with architects influenced the waterfront city development. In the process, both tried to design and develop new structures along water's edge to reinforce the scenic views on the waterfront areas. To build livable built environment, urban designers should a dig deep regarding the geographical, climate, social-culture, and economy condition of the area.

Individual Citizen. In a democratic system, involving citizens in every planning process is crucial. Portland and Baltimore exemplified the democracy implementation in policy decision-making. Voting and majority rule are the bases to determine policies that will affect the future of communities.

Table 1. The degree of Influence of the key actors in the urban waterfront development

\begin{tabular}{|c|c|c|c|c|c|}
\hline Key actors studies & Bilbao & Shanghai & Baltimore & $\begin{array}{l}\text { Portland } \\
\left.\text { (1 } 1^{\text {st }} \text { phase }\right)\end{array}$ & $\begin{array}{l}\text { Portland } \\
\qquad\left(2^{\text {nd }}\right. \\
\text { phase })\end{array}$ \\
\hline Political leader & $\infty$ & - & $\infty$ & $\infty$ & $\infty$ \\
\hline Private business & • & • & ○ & ○ & $\bullet$ \\
\hline $\begin{array}{l}\text { Independent } \\
\text { organizations } \\
\text { (NGOs) }\end{array}$ & $\infty$ & O & $\infty$ & $\bullet$ & $\infty$ \\
\hline $\begin{array}{l}\text { Individual } \\
\text { citizen }\end{array}$ & $\infty$ & O & $\bullet$ & 0 & 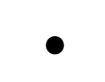 \\
\hline $\begin{array}{l}\text { Urban } \\
\text { designer/planner }\end{array}$ & $\bullet$ & $\infty$ & $\infty$ & $\infty$ & $\infty$ \\
\hline
\end{tabular}

\section{Public participation role in the waterfront development}

This section attempts to examine the existence of public participants in each case study and to understand to what extent the public contributed to environment, economy, and social values in reshaping the direction of urban waterfront development. The time needed to reach the intended goals is 
also studied in this section.

In Bilbao case, local administrators acted as the initiator to revitalize an alarming decline of Nervon River. The first step conducted by the local government for remaking the image of the city was by holding design competitions that invited famous urban planners and architects. A series of the successful initial projects had generated tremendous local, national, and international publicity. The initiation started at the end of 1980s and the project began to obtain result after ten years. But there were questions over the privatization of planning and a more focus effort on economic feasibility (Gomez, 1998).

Shanghai waterfront revitalization has given an example about the very limited role of the citizens. The remarkable achievement also took about ten years since its initiation in 1990. But someone can argue that Shanghai is blessed by a local government, which has visionary thinking and not shortsighted. Environment and economy recovery is the basis for the revitalization effort in the absence of public participation. However, the local government collaboration with research institutes and private sectors have successfully improved the nature of urban water's edge.

Private businesses hold an important stake in the success story of Baltimore waterfront redevelopment. They successfully revived a neglected waterfront area into a livable community. Initially, the development efforts did not involve citizens since the people moved away from this area. Public participatory then started to be accounted when people were getting some benefits from the waterfront revitalization projects. The majority rule had an important in decisionmaking. Unfortunately, oftentimes, voters mostly voted for economic growth in the expense of environment preservation.

Portland's first phase waterfront development reflected the shortfall of public participatory process when neighborhood groups included those who sought to prevent new development. The groups wanted to preserve the historical values of the city and assumed that by inviting outside developers that were not related to water-dependent activities would degrade the values. These groups had strong influence to citizen and always won the voting to preserve city's historic values. For almost twenty years Portlanders witnessed economy setback to conserve their environment and culture. Positive economic growth in Portland's waterfront development $\left(2^{\text {nd }}\right.$ phase $)$ occurred when the local government began to shift the policy gradually. Later, the shifted policy has gained the citizen sympathy. The economic growth changed the stance of Portlanders in the expense of cultural and environmental values.

In urban waterfront redevelopment, voting and majority rule seem not an absolute requirement that will guarantee the success of a waterfront project. This model of democracy however does not respond to the needs of today's communities and the complex social and political system (Ataöv, 2007). Environmentalist groups concerning to environment share with heritage preservation group was usually represented by few people and less powerful compared to developers or business communities. In reality, sometimes contemporary public participation can be characterized as self-interested, shortsighted, and segregated along class and radical lines, legally sophisticated, and fearful (Berke, et al., 2006).

Despite all the facts above, citizen's participation in an urban waterfront development still held significant importance since the urban development was addressed for citizen prosperity. Good development plan should serve its citizen, and build livable environment and the city planner needs to study the characteristic of community and to get knowledge about it. For that reason, the public should be involved in planning process. The public includes a wide range of potential participants whose interests are not always well defined, but their input can contribute to better information and more accurate identification of issues and goals (Margerum, 2001). The key question is how participants can be a part of the waterfront development process.

\section{Towards an effective participatory process}

Driven by an ambition to develop a leading-tourism destination and the fact that the western has shown the enormous potential of the waterfronts, other countries are in a racing to develop their waterfront areas. Spectacular high-rise residential, commercial and cultural projects have become a global trend to turn abandoned waterfront sites into thriving areas attracting global capital (Lehrer \& Laidley, 2009). This kind of development results in gated developments with limited public access because of the increasing privatization along the waterfronts.

Gentrification is also one of the main issues of these waterfront projects since the projects mostly target wealthy people and displace the existing community. What we can expect from this kind of top-down decision making is inevitably socio-economic polarization and possibly lead to social conflict.

For decades, most of waterfront developments around the world are focused on two main values; i.e. economy and environment. These two values were competing over waterfront's future land-use pattern. Today, reclaiming the waterfront areas as the public space is an emerging issue aimed to open up access along the urban water's edge that had been closed off to the public for decades. The waterfront is considered as a public place where most people live, work, and play on a daily bases in this area. Consequently, environment, economy, and social values all together should be taken into account to achieve a livable waterfront area.

Involving participatory process through the planning process may be considered as one of the best ways to define the future development of waterfront areas. The policymakers should be alert in deciding the direction of waterfront development. The environments must be protected and the identity and unique characteristics of waterfront should be preserved. The policy in developing the waterfront also should support the co-existent of public and private sector needs. The participatory process would give equal opportunities for everybody involved; as a result, positive solutions could be developed through discussion.

How participants can be part of the waterfront development process and how they are positioned are not the simple tasks. To have a practical and positive impact, it is necessary that program planners and future program participants work together to devise a program, which will serve the most crucial needs of program participants (Nichols, 2002).

Each of local government, private businesses, citizen activists, individual citizens, and urban planner plays an 
important role in a waterfront revitalization project. Local government is the key actor to initiate the project when the city part declines. Citizen activists are crucial to represent the minority and act as a watchdog in project development. Financial support from private business is also important for the waterfront development. Citizens play a role to guide the development and they are as the one of the indicators in determining whether the waterfront revitalization project is success or failed. Urban planner role is very essential to balance among different economy, environment, and social values as well as to facilitate the public and private interests. Planners have to ensure the co-existent of public and private to build a livable urban waterfront.

From four waterfront development stories presented above, a participatory planning model was synthesized and generated to have a sustainable waterfront development project (see figure 1). This model was based on an ideal condition of each key actor. The benefit and the challenge by the absence of the ideal condition was discussed as well. This model generally has three important stages, from inputs, throughputs, to outputs. The input stage refers to a project initiation step and participatory process. The throughput consists of technical, analytical, and evaluation process. Then, the model will result a series of master plans, development plans, and a set of policies as the outputs.

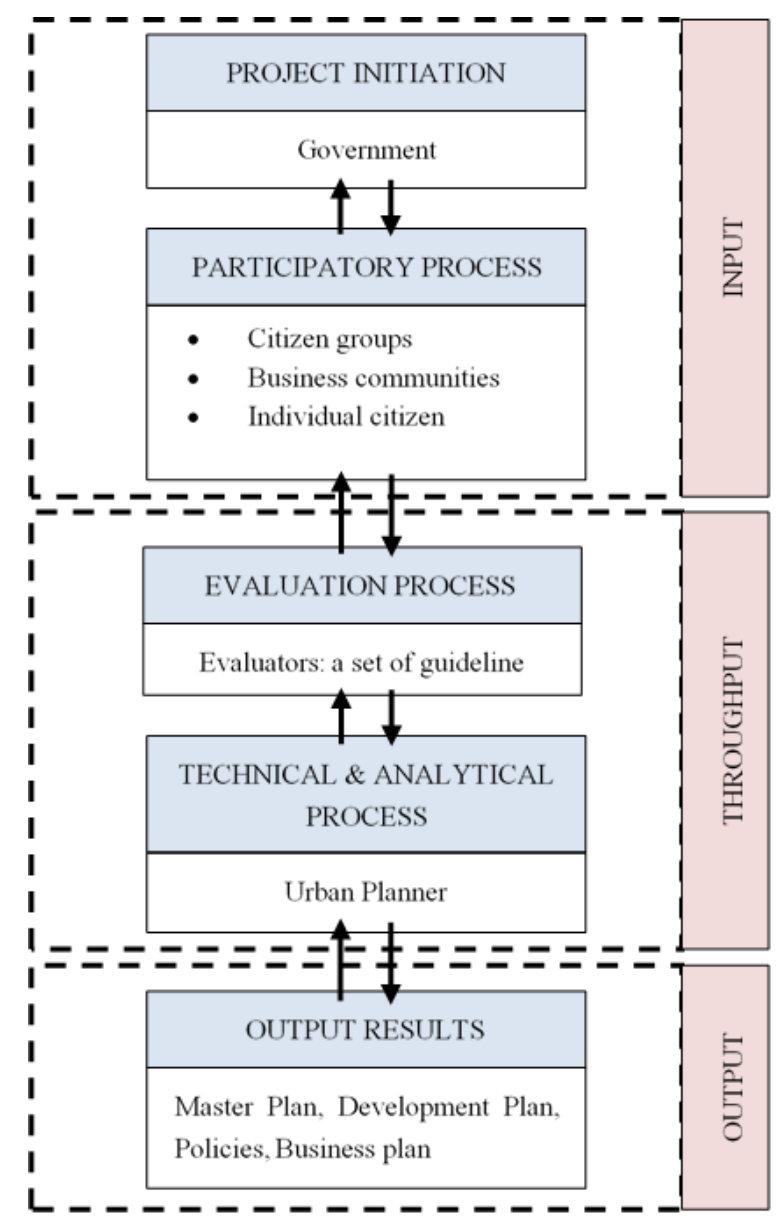

Fig. 1. The proposed participatory planning model

Anybody, from government to individual citizen, who sees a great potential on the urban waterfront may speak up to initiate a waterfront development project. Environmentalists, historical preservation groups, or business communities also might propose an essential revitalization effort to re-address the declining condition. Afterwards, the local administrator needs to kick-off the projects by facilitate participatory process and technical and evaluation process. A special talent who advocate conservation, economic, and social values is required to balance the interests of different groups, including those of foreigners bringing financial and technical assistance to the region (Ericson, 2006), and having a leader who demonstrates that required skill is a real challenge.

The second part of the input phase is the participatory itself. At least, there are two important factors that might contribute to the successful of a project. First is how to select potential participants that could provide vital information for the projects, and the second is how to balance between conservation and economic values that need to be addressed to restore the dilapidated urban waterfront. Working with heterogeneous groups and plural interests often require much time and patience to build consensus among participants. The difficulty, naturally, lies in the careful choice and the amount, so that the project is not dominated by a consolidated dual in term of commerce entertainment, which is particularly dear to many North America waterfront developments (Bruttomesso, 2001).

The result of participatory process is a bulk of information, aspiration, and even critics that need to be compiled together to come up with a clear direction of the proposed waterfront development. Filtering amount of information and presenting it in different way to suit different competed groups is a real challenge. More frequently, the end-product might be more architecturally-oriented and ignore the process that laid the foundation for its creation (Marshall, 2001).

In spite of engaging a voting procedure to judge the input, an evaluation method by utilizing evaluators to examine all the input is preferable since it is more efficient and effective. Evaluators are the knowledgeable and well-trained people as well as trustworthy and highly committed to program. Output of this phase is a set of guideline for the proposed waterfront development. To mitigate potential problems caused by a closeness relationship of the evaluators to a particular group, the use of an external evaluator is suggested (Nichols, 2002). The evaluator involvement starts from the input process as a facilitator, through the design process. If possible, it is along with citizens to guide the implementation.

In the next stage, urban planners will work to utilize the guideline for analytical and technical process to generate development plans. The master plans, business plans, development plans, or policies produced by this process will serve forth as a community consensus-building tool that can rally and unite stakeholders and government to act. The output result should be able to reflect the diversity and flexibility of socio-economic, cultural, aesthetic and environmental arguments advanced to justify the massive public cost and private gain, which often accompany the waterfront developments (Lehrer \& Laidley, 2009).

The common problem having revealing the plans is vagueness terms used in plans and policies, which might lead to misperception, Shaw (2001) argued that it is mandatory for urban waterfront development plans to clearly describe a conservation plan in concert with a business plan, 
zonesrequiring special treatment and the nature of that treatment.

\section{Conclusion}

An urban waterfront development is a unique type of urban revitalization effort. The very sensitive and complex environmental issues in this area need a great cost to revitalize. Waterfront development efforts should be directed to open up access along the shoreline to general public and avoid urban segregation, along with economy and environment consideration to achieve a sustainable and livable urban waterfront. Public participation needs to be addressed carefully since voting and majority rules are not always an absolute requirement that will guarantee the success of a waterfront project. From the discussion about several urban waterfront case studies presented above, there is a raised question of the compatibility of the participatory method in a waterfront development project. In some cases, citizens are driven by specific interest groups with their own goals and objectives. At least, there are five key actors that need to work together to develop a sustainable waterfront project. Those are political leaders, private businesses, independent organizations, urban designers/planners, and the citizens themselves. Urban waterfronts are public spaces where all citizens should have an equal access along the water's edge. Although involving public participants might require more time and attention, the waterfront development cannot be left up to policy makers or urban planners alone. Citizen involvement is essential to address social problems and human needs in relation to urban water's edge revitalization. The participatory planning model was redrawn in this paper to better accommodate citizen's aspiration in an urban waterfront development. The proposed planning model includes three phases. The first phase is the participatory process itself, where all elements of a city are invited to discussions to provide their input about the proposed project. In the second phase, an evaluation method by utilizing experts is preferable since it is more efficient and effective as well. The product of this phase is a set of guideline for the proposed urban waterfront development. Later, urban planners are responsible for making the development plans based on the guideline as set by the evaluators. Ideally, the evaluator involvement should start from the input process as a facilitator, throughout the whole process.

\section{References}

Acuto, M. (2010). High-rise Dubai urban entrepreneurialism and the technology of symbolic power. Cities, 27(4), 272-284.
Al-But'hie, I. M., \& Saleh, M. A. E. (2002). Urban and industrial development planning as an approach for Saudi Arabia: the case study of Jubail and Yanbu. Habitat International, 26(1), 1-20. Al.

Ataöv, A. (2007). Democracy to become reality: Participatory planning through action research. Habitat International, 31(3-4), 333-344.

Berke, P. R., Godschalk, D. R., Kaiser, E. J., \& Rodriguez. (2006). Urban Land Use Planning. Illinois: University of Illinois Press.

Breen, A., \& Rigby, D. (1994). Waterfronts: Cities Reclaim Their Edge. United States: Kim Hupp Lee.

Bruttomesso, R. (2001). Complexity on the Urban Waterfront. In R. Marshall, Waterfronts in Post-industrial Cities (pp. 39-50). London: Spon Press.

Daamen, T. A., \& Vries, I. (2013). Governing the European Port-city Interface: Institutional Impacts on Spatial Projects between City and Port. Journal of Transport Geography, 27, 4-13.

Davis, E. C. (2001). Preserving Municipal Waterfronts in Maine for WaterDependent Uses: Tax Incentives, Zoning, and the Balance of Growth and Preservation. Ocean \& Coastal LJ, 6, 141-185.

Ericson, J. A. (2006). A Participatory Approach to Conservation in the Calakmul Biosphere Reserve, Campeche, Mexico. Landscape and Urban Planning, 74, 242-266.

Friedman, J. (2005). Globalization and the Emerging Culture of Planning. Progress in Planning, 64, 183-234.

Gomez, M. V. (1998). Reflective Images: The Case of Urban Regeneration in Glasgow and Bilbao. International Journal of Urban and Regional Research, 22(1), 106-121.

Hagerman, C. (2007). Shaping Neighborhoods and Nature: Urban Political Ecologies of Urban Waterfront Transformations in Portland, Oregon. Cities, 24(4), 285-297.

Lehrer, U., \& Laidley, J. (2009). Old Mega-Projects Newly Packaged? Waterfront Redevelopment in Toronto. International Journal of Urban and Regional Research, 32(4), 786-803.

Margerum, R. D. (2001). Organizational Commitment to Integrated and Collaborative Management: Matching Strategies to Constraints. Environmental Management, 28(4), 421-431.

Marshall, R. (2001). Remaking the Image of the City. In R. Marshall, Waterfronts in Post-Industrial Cities (pp. 53-73). London: Spon Press.

Millspaugh, M. L. (2003). Inner Harbor Story. Urban Land, 62(4), 36-41.

Nichols, L. (2002). Participatory Program Planning: Including Program Participants and Evaluators. Evaluation and Program Planning, 25(1), 1-14.

Rizzo, A. (2013). City profile: Metro Doha. Cities, 31, 533-543.

Wiedmann, F., Salama, A. M., \& Thierstein, A. (2012). From Pre-oil Settlement to Post-Oil Hub the Urban Transformation of Doha. International Symposium of CAUMME 2012 (Contemporary Architecture and Urbanism in the Mediterranean and the Middle East in 2012) (pp. 65-77). Istanbul, Turkey: Yıldız Technical University Printing \& Publishing Center. 